\title{
Anthropometric indices in relation to overweight and obesity among Turkish medical students
}

Pınar Karakaș, Memduha Gülhal Bozkır

Department of Anatomy, School of Medicine, Çukurova University, Adana, Turkey

Submitted: 13 May 2011

Accepted: 24 July 2011

Arch Med Sci 2012; 8, 2: 209-213

DOI: 10.5114/aoms.2012.28546

Copyright @ 2012 Termedia \& Banach

\section{Abstract}

Introduction: The aim of this study was to present the reference anthropometric data associated with obesity for cardiovascular risk and metabolic diseases for healthy young adults in a Turkish population.

Material and methods: The study group consisted of 1163 second-year medical students (650 women, 513 men) aged 20-25 years from Çukurova University in Adana and the measurements were made using a flexible standard measuring tape. The data were collected during the period 2007-2011.

Results: From 1163 medical students, the mean values of body mass index, circumferences of waist, hip, neck, mid-arm, thigh and calf were $20.89 \pm 1.6 \mathrm{~kg} / \mathrm{m}^{2}$, $73.15 \pm 5.1 \mathrm{~cm}, 95.35 \pm 4.8 \mathrm{~cm}, 30.32 \pm 1.37 \mathrm{~cm}, 24.12 \pm 1.75 \mathrm{~cm}, 47.23 \pm 3.26 \mathrm{~cm}$ and $34.36 \pm 2.19 \mathrm{~cm}$ respectively in women, while the same measurements were $21.98 \pm 1.67 \mathrm{~kg} / \mathrm{m}^{2}, 77.73 \pm 5.81 \mathrm{~cm}, 95.64 \pm 4.81 \mathrm{~cm}, 35.61 \pm 1.43 \mathrm{~cm}, 25.60$ $\pm 1.84 \mathrm{~cm}, 44.10 \pm 3.26 \mathrm{~cm}$ and $34.92 \pm 2.08 \mathrm{~cm}$ respectively in men. Moreover, waist to hip ratio, waist to height ratio and neck to height ratio were respectively $0.76,0.44$ and 0.18 in women and $0.81,0.43$ and 0.19 in men.

Conclusions: The precise knowledge of anthropometric data could be used as reference values for evaluating the body composition and fat distribution of Turkish young people.

Key words: anthropometry, body mass index, circumference measurements, obesity.

\section{Introduction}

Obesity is a rapidly growing health problem throughout the world and is defined as a body mass index (BMI) $30 \mathrm{~kg} / \mathrm{m}^{2}$ or higher. Obesity and body fat distribution are important predictors of coronary heart disease $[1,2]$. Moreover, they are associated with several chronic diseases including hyperlipidemia, hyperinsulinemia and hypertension [2-5]. From a clinical view, estimation of adipose tissue distribution must therefore be considered as important in the evaluation of the patient's cardiovascular risk profile [6]. There are numerous methods of assessing overweight, obesity and fat distribution such as measurements of weight, height, waist, hip, midarm, thigh and calf circumferences and calculations of waist-to-hip ratio, and BMI. For many years, the waist-hip ratio (WHR) was used for evaluation of the body fat distribution. But in some studies, it was reported that waist circumference is more closely associated with the central fat distribution than WHR $[6,7]$. Recently, another anthropometric index, waist-to-height ratio (WHtR), was shown to be better correlated with metabolic risk factors [8-10]. Nevertheless, the best method for evaluation of the fat distribution is computed tomography. However, computed tomog-
Corresponding author: Assoc. Prof. Pınar Karakaș Dr, MD

Department of Anatomy School of Medicine Çukurova University 01330 Adana, Turkey Phone: +90 32233860 60-3489

Fax: +90 3223386572 E-mail: pkarakas@cu.edu.tr 
raphy $(\mathrm{CT})$ is impractical as a routine method for measuring because of radiation exposure and high cost $[6,11-14]$. Therefore, a practical alternative to CT and magnetic resonance imaging (MRI) is anthropometry. Instruments for measuring the anthropometric dimensions are portable and inexpensive, and procedures are noninvasive and easily applied. Although obesity results in metabolic abnormalities, upper-body obesity is more strongly associated with some pathologies, such as glucose intolerance, diabetes mellitus and gout, than lower-body obesity. Moreover, in a previous study, neck circumference as an index of upper-body obesity was found to be a simple measure that can be used to identify overweight and obese people. It was also shown that large neck circumference correlated with blood pressure [15].

The aim of the present study was therefore to identify reference anthropometric indices related to cardiovascular risks and metabolic diseases in healthy women and men in a Turkish group and compare them with other populations.

\section{Material and methods}

The study group consisted of 1163 (650 women, 513 men) second-year medical students aged 2025 years in the Çukurova University, School of Medicine during the period 2007-2011. The study was approved by the ethics committee of the School of Medicine, Çukurova University. A questionnaire form was prepared. The basis of this questionnaire was to obtain the medical history of the study group. It included biographical data, lifestyle behaviors such as cigarette smoking and alcohol use, and medical history of cardiovascular diseases, high blood pressure, and diabetes mellitus. Weight was measured with electronic scales to the nearest $0.1 \mathrm{~kg}$ wearing minimal clothing without shoes and height was measured to the nearest millimeter in bare feet with a wall-mounted stadiometer. Then body mass index (BMI; in $\mathrm{kg} / \mathrm{m}^{2}$ ) was calculated. Circumference measurements were made with a flexible standard measuring tape in the plane orthogonal to the long axis of the body segment being measured. Waist circumference (WC) was measured midway between the lowest rib and top of the iliac crest at the end of gentle expiration. Hip circumference $(\mathrm{HC})$ was evaluated at the maximum protuberance of the buttocks. Moreover, circumferences at the mid-arm (AC), mid-thigh (TC) and calf (CC) were recorded. Neck circumference (NC) was measured in the middle of the neck between the mid-cervical spine and mid-anterior neck. However, in men with a laryngeal prominence, it was measured just below the prominence. Since taller people are expected to have a larger neck, it is normalized by calculating the neck/height ratio. After these measurements waist-to-hip ratio and waistto-height ratio were also calculated.
The data were divided into two groups according to gender and statistical analysis was performed with SPSS 10.0. From these measurements, means, standard deviations, and minimum and maximum values were evaluated.

\section{Results}

The baseline characteristics of the 650 women and 513 men are shown in Table I. When we analyzed the data in this study, from the questionnaire, it was found that nobody had a history of cardiovascular or other diseases in both genders. From 513 men, 106 (20.66\%) smoked cigarettes and 60 (11.69\%) used alcohol, while in women, 70 (10.76\%) of 650 used cigarettes and 20 (3.1\%) of them used alcohol. No significant differences were found between the anthropometric indices of smokers and non-smokers. Additionally, from our measurements, the mean age, HC, CC and WHtR levels were similar in women and men among the medical students. Compared to women, men were heavier, taller, and had higher WC, NC, AC, TC and WHR (Table I). The mean values of BMI were $20.89 \mathrm{~kg} / \mathrm{m}^{2}$ in women and $21.98 \mathrm{~kg} / \mathrm{m}^{2}$ in men. The mean values of the circumferences of waist, hip, arm, thigh, calf and neck were $73.15 \pm 5.1 \mathrm{~cm}, 95.35 \pm 4.8 \mathrm{~cm}$, $24.12 \pm 1.7 \mathrm{~cm}, 47.23 \pm 3.3 \mathrm{~cm}, 34.36 \pm 2.2 \mathrm{~cm}$ and $30.32 \pm 1.4 \mathrm{~cm}$ respectively in women, and 77.73 $\pm 5.8 \mathrm{~cm}, 95.64 \pm 4.8 \mathrm{~cm}, 25.6 \pm 1.8 \mathrm{~cm}, 44.1 \pm 3.3 \mathrm{~cm}$, $34.92 \pm 2.1 \mathrm{~cm}$ and $35.61 \pm 1.4 \mathrm{~cm}$ respectively in men. Finally, the means of the ratios of waist-hip, waist-height and neck-height were estimated as $0.76,0.44$ and 0.18 respectively in women, and 0.81 , 0.43 and 0.19 respectively in men.

\section{Discussion}

The present study provides a summary of anthropometric values related to cardiovascular risks and metabolic disorders in healthy young Turkish people and compares them with other populations.

Based on the meeting of the International Obesity Task Force, a BMI of $18.5-24.9 \mathrm{~kg} / \mathrm{m}^{2}$ is defined as the optimal range, BMI of 25 to $29.9 \mathrm{~kg} / \mathrm{m}^{2}$ is defined as overweight, and $B M I \geq 30 \mathrm{~kg} / \mathrm{m}^{2}$ is defined as obese. Conversely, $\mathrm{BMI} \leq 18.5 \mathrm{~kg} / \mathrm{m}^{2}$ is defined as underweight [16-18]. Obesity is associated with several risk factors for heart disease and other chronic diseases including hyperlipidemia, hyperinsulinemia, hypertension and atherosclerosis [2]. Unfortunately, the prevalence and incidence of obesity are increasing rapidly in both developed and developing countries $[2,14,19,20]$. Because of public health importance, the trends in young adult obesity should be monitored. In literature findings, there were mean values of weight and height of study groups from different countries. But the BMI $\left(\mathrm{kg} / \mathrm{m}^{2}\right)$ is widely used in definition of adult obesity. Addi- 
Table I. Anthropometric indices of healthy women and men

\begin{tabular}{|c|c|c|c|}
\hline Anthropometric index & Sex & Mean \pm standard deviation & Minimum-maximum \\
\hline \multirow[t]{2}{*}{ Age [years] } & Women & $21.41 \pm 0.9$ & $20-25$ \\
\hline & Men & $21.69 \pm 1.27$ & $20-25$ \\
\hline \multirow[t]{2}{*}{ Height $[\mathrm{cm}]$} & Women & $164.86 \pm 4.8$ & $156-178$ \\
\hline & Men & $178.63 \pm 5.3$ & $165-188$ \\
\hline \multirow[t]{2}{*}{ Weight [kg] } & Women & $56.8 \pm 5.0$ & $47-68$ \\
\hline & Men & $70.2 \pm 6.78$ & $54-85$ \\
\hline \multirow[t]{2}{*}{ BMI $\left[\mathrm{kg} / \mathrm{m}^{2}\right]$} & Women & $20.89 \pm 1.6$ & $18.6-24.6$ \\
\hline & Men & $21.98 \pm 1.67$ & $18.6-24.9$ \\
\hline \multirow[t]{2}{*}{$W C[\mathrm{~cm}]$} & Women & $73.15 \pm 5.1$ & $60-85$ \\
\hline & Men & $77.73 \pm 5.81$ & $67-91$ \\
\hline \multirow[t]{2}{*}{$\mathrm{HC}[\mathrm{cm}]$} & Women & $95.35 \pm 4.8$ & $87-113$ \\
\hline & Men & $95.64 \pm 4.81$ & $86-105$ \\
\hline \multirow[t]{2}{*}{$\mathrm{NC}[\mathrm{cm}]$} & Women & $30.32 \pm 1.37$ & $28-33$ \\
\hline & Men & $35.61 \pm 1.43$ & $33-39$ \\
\hline \multirow[t]{2}{*}{$\mathrm{AC}[\mathrm{cm}]$} & Women & $24.12 \pm 1.75$ & $21-28$ \\
\hline & Men & $25.6 \pm 1.84$ & $22-31$ \\
\hline \multirow[t]{2}{*}{$\mathrm{TC}[\mathrm{cm}]$} & Women & $47.23 \pm 3.26$ & $40-58$ \\
\hline & Men & $44.1 \pm 3.26$ & $37-50$ \\
\hline \multirow[t]{2}{*}{$\mathrm{CC}[\mathrm{cm}]$} & Women & $34.36 \pm 2.19$ & $30-40$ \\
\hline & Men & $34.92 \pm 2.08$ & $30-41$ \\
\hline \multirow[t]{2}{*}{ WHR } & Women & $0.76 \pm 4.187 \mathrm{E}$ & $0.69-0.85$ \\
\hline & Men & $0.81 \pm 3.928 \mathrm{E}$ & $0.73-0.93$ \\
\hline \multirow[t]{2}{*}{ WHtR } & Women & $0.44 \pm 3.106 \mathrm{E}$ & $0.38-0.52$ \\
\hline & Men & $0.43 \pm 2.893 \mathrm{E}$ & $0.37-0.49$ \\
\hline
\end{tabular}

$B M I$ - body mass index, WC - waist circumference, $H C$ - hip circumference, NC-neck circumference, $A C$-arm circumference, TC - thigh circumference, $C C$ - calf circumference, WHR - waist-to-hip circumference ratio, WHtR - waist-to-height ratio

tionally, obesity raises surgical morbidity and mortality because of its adverse effects on cardiopulmonary dynamics, wound healing and sedation or anesthesia [21]. In a study including Greek medical students, a high proportion of subjects were overweight (27.6\%) or obese (4.3\%) [16]. A study in Slovakia reported that $16 \%$ of male and $2 \%$ of female medical students had a BMI $>25.0 \mathrm{~kg} / \mathrm{m}^{2}$ [22]. Moreover, an investigation conducted among 154 medical students in South Africa estimated the rates of overweight and obesity as $8.9 \%$ and $2.5 \%$ respectively for Indian and $19.7 \%$ and $4.6 \%$ for black students [23]. In this paper, we document the values of healthy students so both underweight and overweight subjects' anthropometric indices are excluded in this investigation.

For health promotion, waist circumference is becoming preferred for determination of adiposity since this measurement reflects total and abdominal fat accumulation $[14,20,24]$. So this anthropometric variable is used more often to identify risk of cardiovascular diseases and metabolic disorders than BMI $[25,26]$. It was emphasized that waist circumferences greater than $102 \mathrm{~cm}$ in men and greater than $88 \mathrm{~cm}$ in women had a strong correlation with development of several disorders including hypercholesterolemia and hypertension [24]. In addition, waist-to-hip ratio and waist-to-height ratio were widely used for evaluating the regional adipose tissue [6]. However, several researchers have indicated that the waist circumference alone is more closely correlated with the level of abdominal adipose tissue than the WHR $[6,27]$. Conversely, it was noted that waist-to-height ratio was the best simple anthropometric predictor of abdominal fat in previous reports $[8,28]$. Also it was suggested that the boundary value for risk (WHtR-0.5) might be used for both women and men [8, 10, 29]. Ashwell et al. reported that the boundary value of WHtR translated into a simple public health message: "Keep your waist circumference to less than half your height" [8]. Furthermore, it was observed 
that WC in women and WHtR in men were strong indicators for abnormal serum lipids and lipoproteins [16]. In this study, the mean values of waist circumference, waist-to-hip ratio, and waist-toheight ratio were $73.15 \pm 5.1 \mathrm{~cm}, 0.76$ and 0.44 respectively in women, whereas the same indices were $77.73 \pm 5.81 \mathrm{~cm}, 0.81$ and 0.43 respectively in men. In a study including Chinese people, these values were $77.3 \pm 9.4 \mathrm{~cm}, 0.84,0,50$ respectively in women and $83.3 \pm 8.3 \mathrm{~cm}, 0.90,0.50$ respectively in men [30]. In Indians, the mean values of WC and WHR were estimated as $77.4 \pm 12.6 \mathrm{~cm}, 0.82$ respectively in women and $79.6 \pm 11.4 \mathrm{~cm}, 0.86$ in men [31]. In 21-year-old Dutch people, the same indices were $71.3 \mathrm{~cm}$ and 0.75 in women and $79.6 \mathrm{~cm}$ and 0.83 in men respectively [7]. Hill et al. reported these values as $86.6 \mathrm{~cm}, 0.79$ in black women and as $76.1 \mathrm{~cm}, 0.74$ in white women respectively, while in black men they were $87.6 \mathrm{~cm}, 0.84$ and in white men $89.2 \mathrm{~cm}, 0.87$ [13]. According to these values, we found differences in all mean values of Chinese, Indians, and Hill's study group (blacks and whites) compared with our results, having greater values than us. However, Dutch people's mean values are similar to our indices.

Body composition exhibits consistent and substantial change with age. Among the age-related patterns are a decrease in fat-free mass, especially skeletal muscle, an increase in overall adiposity and accumulation of adipose tissue at the middle body. Regarding body changes, age-related loss of muscle mass beginning after early adulthood is reported [32]. Calf circumference is emphasized to be a helpful indicator of fat-free mass and is considered a good indicator of undernourishment $[25,32]$. Furthermore, mid-thigh circumference is also used for lean body weight [32]. When we analyzed our anthropometric indices, the mean values of circumferences of arm, thigh and calf were $24.12 \mathrm{~cm}, 47.23 \mathrm{~cm}, 34.36 \mathrm{~cm}$ in women and $25.6 \mathrm{~cm}, 44.1 \mathrm{~cm}, 34.9 \mathrm{~cm}$ in men respectively. These circumferences were $27.1 \mathrm{~cm}, 53.8 \mathrm{~cm}, 35.7 \mathrm{~cm}$ in women and $28.5 \mathrm{~cm}, 53.1 \mathrm{~cm}, 36.3 \mathrm{~cm}$ in men from the Free University of Brussels [33]. Also, in a study including four racial groups (African American, Asian, white and Hispanic), the same dimensions were reported as $28.9 \mathrm{~cm}, 53.8 \mathrm{~cm}, 35.7 \mathrm{~cm}$ in women and $32.4 \mathrm{~cm}, 55.3 \mathrm{~cm}, 37.8 \mathrm{~cm}$ in men respectively [12]. Differences between circumferences in this study and those of Portman's and Lee's in Brussels, Canada and New York may be explained by socioeconomic and lifestyle differences.

Upper-body obesity is more strongly associated with glucose intolerance, hyperinsulinemia, diabetes, and gout than is lower-body obesity [15]. Neck circumference is determined as an index of upper-body subcutaneous adipose tissue distribution and is related to cardiovascular risk factors. Thus, it was indicated that NC can be used as a simple, easy test to identify overweight or obese patients. Furthermore, measurement of NC has become a part of the physical examination of patients with sleep apnea [34]. It was reported that obesity is believed to predispose to sleep apnea because of mass loading of the upper airway by adipose tissue in the neck [35]. In this study, the mean value of NC was $30.32 \mathrm{~cm}$ in women and $35.61 \mathrm{~cm}$ in men. We found a highly significant difference in this circumference between genders. In literature findings, men had higher values than women as in our report but their mean values were greater than ours $[15,34]$.

In summary, we observe that there are differences between the anthropometric indices of other populations including Chinese, Indian, African American and Hispanic and our population. However, there are some similar values in some indices in Dutch people and in our group. We think that this diversity could depend on several factors such as genetic variables, race, nutritional status, different socioeconomic-cultural characteristics and also lifestyle differences.

The World Health Organization (WHO) emphasizes the need for population-specific reference values. Furthermore, since adipose tissue has different distributions in women and men, the data should be presented as gender-specific means with standard deviations for each index [25]. Genetic, environmental and ethnic factors can all influence the degree of risks associated with excess body weight. Given the health cost implications of diseases such as diabetes mellitus, hypertension, dyslipidemia, coronary heart disease and cancer, which are closely associated with overweight/obesity, these data will facilitate the development of a preventive strategy for these health care problems. Thus, young adults who are identified as being at high risk of excess adiposity could be encouraged to make lifestyle changes, such as increased physical activity, and be given nutrition education and dietary counseling [11]. Moreover, body composition is commonly investigated in epidemiological, clinical and population studies. Reliable methods for measurement of body fat and fat distribution are therefore important and anthropometry is the most widely used method. The distinct advantages of anthropometry, which we used in this paper, are that it is portable, non-invasive and inexpensive.

In conclusion, we think that precise knowledge concerning the anthropometric indices of healthy young adults correlated with cardiac and metabolic pathologies could be essential for determining public health and providing reference data and can be used as reference values for evaluating the body composition and fat distribution of young Turkish people. As a result, we believe that the data presented in this study will provide useful references for clinical practice and epidemiological studies for assessment of obesity. 


\section{References}

1. Gustat J, Elkasabany A, Srinivasan S, Berenson GS. Relation of abdominal height to cardiovascular risk factors in young adults. The Bogalusa Heart study. Am J Epidemiol 2000; 151: 885-91.

2. Cole TJ, Bellizzi MC, Flegal KM, Dietz WH. Establishing a standard definition for child overweight and obesity worldwide: international survey. BMJ 2000; 320: 1240-3.

3. Symonides B, Jedrusik P, Artyszuk L, Grybos A, Dzilinski P, Gaciong Z. Different diagnostic criteria significantly affect the rates of hypertension in 18-year-old high school students. Arch Med Sci 2010; 6: 689-94.

4. Delavari A, Kelishadi R, Forouzanfar MH, Safaei A, Birjandi F, Alikhani S. The first cut off points for generalized and abdominal obesity in predicting lipid disorders in a nationally representative population in the Middle East: The National Survey of Risk Factors for non-communicable diseases of Iran. Arch Med Sci 2009; 5: 542-9.

5. Kostulski A, Pawelczyk T, Rabe-Jablonska J. The risk of significant body weight gain and abdominal obesity during short term treatment with olanzepine. Arch Med Sci 2009; 5: 259-66.

6. Pouliot MC, Despres JP, Lemieux S, et al. Waist circumference and abdominal sagittal diameter: best simple anthropometric indexes of abdominal visceral adipose tissue accumulation and related cardiovascular risk in men and women. Am J Cardiol 1994; 73: 460-8.

7. Fredriks AM, van Buuren S, Fekkes M, Verloove-Vanhorick SP, Wit JM. Are age references for waist circumference, hip circumference and waist-hip ratio in Dutch children useful in clinical practice? Eur J Pediatr 2005; 164: 216-22.

8. Ashwell M, Gibson S. Waist to height ratio is a simple and effective obesity screening tool for cardiovascular risk factors: analysis of data from the British national diet and nutrition survey of adults aged 19-64 years. Obes Facts 2009; 2: 97-103.

9. Lee CM, Huxley RR, Wildman RP, Woodward M. Indices of abdominal obesity are better discriminators of cardiovascular risk factors than BMI: a meta-analysis. J Clin Epidemiol 2008; 61: 646-53.

10. Hsieh SD, Yoshinaga $\mathrm{H}$. Waist/height ratio as a simple and useful predictor of coronary heart disease risk factors in women. Int Med 1995; 34: 1147-52.

11. Taylor RW, Jones IE, Williams SM, Goulding A. Evaluation of waist circumference, waist-to-hip ratio, and the conicity index as screening tools for high trunk fat mass, as measured by dexa in children aged 3-19 y. Am J Clin Nutr 2000; 72: 490-5.

12. Lee RC, Wang Z, Heo M, Ross R, Janssen I, Heymsfield SB. Total-body skeletal muscle mass: development and crossvalidation of anthropometric prediction models. Am J Clin Nutr 2000; 72: 796-803.

13. Hill JO, Sidney S, Lewis CE, Tolan K, Scherzinger AL, Stamm ER. Racial differences in amounts of visceral adipose tissue in young adults: the CARDIA study. Am J Clin Nutr 1999; 69: 381-8.

14. Valsamakis G, Chetty R, Anwart A, Banerjee AK, Barnett $A$, Kumar S. Association of simple anthropometric measures of obesity with visceral fat and the metabolic syndrome in male Caucasian and Indo-Asian subjects. Diabet Med 2004; 21: 1339-45.

15. Ben-Noun L, Laor A. Relationship between changes in neck circumference and changes in blood pressure. AJH 2004; 17: 409-14

16. Bertsias G, Mammas I, Linardakis M, Kafatos A. Overweight and obesity in relation to cardiovascular disease risk factors among medical students in Crete, Greece. BMC Public Health 2003; 3: 3.

17. International Obesity Task Force. Obesity: preventing and managing the global epidemic. Report of WHO consultation on obesity. Geneva, World Health Organization 1998.

18. WHO. Obesity and Overweight. Fact Sheet NO 311.2011.

19. Friedman JM. Obesity in the new millennium. Nature 2000; 404: 632-4.

20. Chan DC, Watts GF, Barrett PHR, Burke V. Waist circumference, waist-to-hip ratio and body mass index as predictors of adipose tissue compartments in men. Q J Med 2003; 96: 441-7.

21. de Jong RH. Body mass index: risk predictor for cosmetic day surgery. Plast Reconstr Surg 2001; 108: 556-61.

22. Baska T, Straka S, Mad'ar R. Smoking and some life-style changes in medical students-Slovakia, 1995-1999. Cent Eur J Public Health 2001; 9: 147-9.

23. Morar N, Seedat YK, Naidoo DP, Desai DK. Ambulatory blood pressure and risk factors for coronary heart disease in black and Indian medical students. J Cardiovasc Risk 1998; 5: 313-8.

24. Lean MEJ, Han TS, Seidell JC. Impairment of health and quality of life in people with large waist circumference. Lancet 1998; 351: 853-6.

25. Barbosa AR, Souza JMP, Lebrao ML, Laurenti R, Marucci MFN. Anthropometry of elderly residents in the city of Sao Paulo, Brazil. Cad Saude Publica Rio de Janeiro 2005; 21: 1929-38.

26. Dalton M, Cameron AJ, Zimmet PZ, et al. Waist circumference, waist-hip ratio and body mass index and their correlation with cardiovascular disease risk factors in Australian adults. Intern Med 2003; 254: 555-63.

27. Seidell JC, Oosterlee A, Deurenberg P, Hautvast JGAJ, Ruijs JHJ. Abdominal fat depots measured with computed tomography: effects of degree of obesity, sex, and age. Eur J Clin Nutr 1988; 42: 805-15.

28. Ashwell M, Cole TJ, Dixon AK. Ratio of waist circumference to height is strong predictor of intraabdominal fat. BMJ 1996; 313: 559-60.

29. Hsieh SD, Muto TM. The superiority of waist-to-height ratio as an anthropometric index to evaluate clustering of coronary risk factors among non-obese men and women. Prev Med 2005; 40: 216-20.

30. Patel S, Unwin N, Bhopal R, et al. A comparison of proxy measures of abdominal obesity in Chinese, European and South Asian adults. Diabet Med 1999; 16: 853-60.

31. Dudeja V, Misra A, Pandey RM, Devina G, Kumar G, Vikram NK. BMI does not accurately predict overweight in Asian Indians in northern India. Br J Nutr 2001; 86: 105-12.

32. McLorg P. Anthropometric patterns in middle-aged and older rural Yucatec Maya women. Ann Hum Biol 2005; 32: 487-97.

33. Poortmans JR, Boisseau N, Moraine JJ, Moreno-Reyes R, Goldman S. Estimation of total-body skeletal muscle mass in children and adolescents. Med Sci Sports Exer 2005; 37: 316-22.

34. Dancey DR, Hanly PJ, Soong C, Lee B, Shepard J, Hoffstein V. Gender differences in sleep apnea: the role of neck circumference. Chest 2003; 123: 1544-50.

35. Mortimore IL, Marshall I, Wraith PK, Sellar RJ, Douglas NJ. Neck and total body fat deposition in nonobese and obese patients with sleep apnea compared with that in control subjects. Am J Resp Crit Care Med 1998; 157: 280-3. 